\title{
The New Zealand Rugby Injury and Performance Project: V. Epidemiology of a season of rugby injury
}

\author{
Y N Bird, A E Waller, S W Marshall, J C Alsop, D J Chalmers, D F Gerrard
}

Injury Prevention

Research Unit,

Department of

Preventive and Social

Medicine, Medical

School, University of

Otago, Dunedin, New

Zealand

Y N Bird

J C Alsop

D J Chalmers

School of Physical

Education, University

of Otago, Dunedin,

New Zealand

Y N Bird

D F Gerrard

Department of

Emergency Medicine,

School of Medicine,

University of North

Carolina at Chapel

Hill, USA

A E Waller

Injury Prevention

Research Center,

University of North

Carolina at Chapel

Hill, USA

A E Waller

S W Marshall

Department of

Epidemiology, School

of Public Health,

University of North

Carolina at Chapel

Hill, USA

S W Marshall

Correspondence to:

Yvonne Bird, Rugby Injury and Performance Project,

Injury Prevention Research

Unit, Department of

Preventive and Social

Medicine, University of

Otago Medical School, PO

Box 913, Dunedin, New

Zealand.

Accepted for publication

10 June 1998

\begin{abstract}
Objective-To describe the incidence, nature, and circumstances of injury experienced by a cohort of rugby union players during a full competitive club season.

Methods-A prospective cohort study followed up 356 male and female rugby players throughout the 1993 competitive club season. Players were interviewed by telephone each week to obtain information on the amount of rugby played and the injury experienced.

Results-Detailed information was collected for 4403 player-games and 8653 player-practices. A total of 671 injury events were reported, of which 569 were rugby related. The injury rate for games was higher than that for practices (rate ratio 8.3). At 10.9 injuries per 100 playergames, males had a higher rate of injury than females at 6.1 injuries per 100 playergames $(p<0.001)$. Injury rates varied by position, with male locks (13.0 injuries per 100 player-games) and female inside backs (12.3 injuries per 100 player-games) having the highest rate in their respective sexes. The lower limb was the body region most often injured in games $(42.5 \%)$ and practices $(58.4 \%)$. Sprains/strains were the most common type of injury in games $(46.7 \%)$ and practices $(76.1 \%)$. In games the tackle was the phase of play in which the most injuries occurred $(40 \%)$, followed by rucks $(17 \%)$ and mauls $(12 \%)$. Thirteen per cent of game injury events were the result of foul play.

Conclusions-Rugby injury was common among the study subjects and varied according to grade and gender. Identifying the causes of injuries in the tackle, lower limb injuries, and dealing with the issue of foul play are priority areas for the prevention of rugby injury.

(Br F Sports Med 1998;32:319-325)
\end{abstract}

Keywords: rugby union; epidemiology; injury rate; women

Rugby union is a full-body contact game with many injuries resulting from extrinsic forces. Impact, collision at speed, and body contact are an inherent part of the sport and can result in significant musculoskeletal trauma. Closed head injury and concussion, joint dislocations, and fractures represent the more serious end of the spectrum. Muscle contusions, ligament sprains, and similar soft tissue damage are the less severe yet more commonly seen injuries resulting from rugby participation. ${ }^{1-4}$
In New Zealand, rugby union is considered by many to be the national sport. It also has the highest incidence of injury of all the major sports. ${ }^{56}$ Internationally, a number of studies have been undertaken, using a variety of approaches, to determine the incidence, nature, and circumstances of injury in rugby. ${ }^{1-3} 7-12$ These studies have generally focused on premier level men, though one described injuries to women players. ${ }^{10}$ The increasing popularity of rugby for women places them at risk of receiving similar injuries. ${ }^{10}$

Differences in the definition of injury in these studies make comparisons between them difficult. Most incorporate inability to play or practice after the incident as criteria for counting a case. Others identify medical attention as an alternative criterion for inclusion. In addition to this difficulty, the reporting of injury incidence varies between studies. Some studies report rates as "player-injury rate per 1000 player-hours", 38 while others use a playergames format. ${ }^{210}$ Most have reported the distribution of injury by playing position,,$^{1-4} 712$ but none has reported incidence rates by position.

The tackle has been reported as the phase of play in which most injuries occur. ${ }^{1-37}$ The issue of foul play was not considered in the above mentioned studies, with two exceptions. Dalley et $a l^{11}$ reported a reduction in foul or illegal play compared with an earlier study, ${ }^{7}$ and Lewis reported a high incidence of foul play. ${ }^{10}$ Physiological fatigue has been suggested as a contributing factor to rugby injury and may be reflected in the time course of injuries within a game. $^{912}$ It is argued that more injuries should occur during the second half of a match when players are fatigued. ${ }^{12}$

The Rugby Injury and Performance Project (RIPP), a prospective cohort study conducted in Dunedin, New Zealand, was undertaken to investigate risk and protective factors for rugby injury in order to develop potential injury prevention measures. ${ }^{13}$ The previous injury experience of the cohort was reported in an earlier paper. ${ }^{4}$ The purpose of this paper is to describe the incidence, nature, and circumstances of injury experienced by the players during a full competitive club rugby season. We hypothesised that the incidence of injury would be higher for males than for females; would be higher in higher grades; would be higher in games than in practices; and would not differ significantly between positions.

\section{Methods}

The design of the RIPP has been described in detail elsewhere. ${ }^{13}$ In summary, a cohort of 356 male and female rugby players was followed up 
throughout the 1993 competitive club season. The source group for the RIPP was all people playing competitive club rugby in Dunedin, New Zealand, during the 1993 winter season. Because of the dynamic state of team composition before the season, it was impossible to draw a random sample from the source group. Instead, specific teams were selected and invited to join the study. Two of the 22 invited teams declined participation because of scheduling conflicts. The remainder agreed to participate. Teams were selected to represent the diversity of the playing population, and therefore included female players, some of whom were relatively new to the sport. Players in the cohort came from the following grades: first XV schoolgirls and schoolboys (under 18/under 19 grades), colts (under 21), senior A and $\mathrm{B}$ men, and senior women. The number of games organised over the season for these grades ranged from eight for the schoolgirls to 18 for the senior A men. There were a high number of tertiary students in this cohort which might have impacted on the number of games played. The points in the season where student holidays occurred coincided with a drop in contact rates. However, the contact rate was still relatively high with at least $70 \%$ contact rate at weeks $11-13$ and just under $90 \%$ at week $19 .{ }^{13}$ The club rugby season in Dunedin is organised to take student holidays into account, so games are not missed by players.

At the start of the season, information on potential risk and protective factors was obtained by a self administered questionnaire and an anthropometric and physical fitness assessment. Players were telephoned weekly throughout the club season to obtain information on the amount of rugby played and injury experienced. This paper describes the injury experience of the cohort as obtained from the weekly interviews.

Detailed information was collected for all injury events that caused the player to seek medical attention or to miss at least one scheduled game or team practice. This included information on the site and type of injury, phase of play, playing position, and the involvement of foul play. Because of difficulties in obtaining referee reports information about foul play was reported by the players themselves. This is based on the definition of foul play in the laws of the game. If multiple injuries were sustained the details of each injury were recorded. For example, an impact to a player's head that resulted in a facial laceration and concussion would constitute one injury event with information on two injuries being recorded. Players were asked if this was an injury they had told the interviewer about before, and details were collected for new injuries only. The use of the terms injury incidence and injury incidence rate as reported in this paper is based on the definition provided by Last. ${ }^{14}$ As a measure of severity, injuries were coded according to the Abbreviated Injury Scale. ${ }^{15}$ Sufficient information was obtained on 565 rugby related injuries to be assigned a severity score.
This paper reports on injuries associated with scheduled competition play. Tournament games and other informal play occurring after the competitive club season were excluded. Players were assigned to a single positional category based on the position in which they played most often. Over $90 \%$ of participants played in the same position for the whole season. Calculation of injuries per unit time exposure for each position was not possible because data on the exact time spent in each playing position were unavailable.

Team positions were grouped into the following categories: $(a)$ front row: props (two) and hooker; (b) locks (two); (c) loose forwards: flankers (two) and number eight; (d) inside backs: halfback and first-five-eighth; $(e)$ centre backs: second-five-eighth and centre; $(f)$ outside backs: wings (two) and full back.

\section{STATISTICAL ANALYSES}

Of the 356 players recruited into the cohort, eight were not followed up because of incomplete consent, not having a telephone, or living/ travelling out of Dunedin. A further three players who did not participate in any games or practices during the season were also excluded. Information is presented here for 345 players (258 males, 87 females) who participated in rugby and were followed up throughout the season. Analyses by grade were restricted to competitive club grades. Five players who were in the senior B grade at the time of recruitment but subsequently played in lower social grades were therefore excluded when analyses were performed by grade. In the calculation of incidence rates 29 injuries were excluded because the corresponding exposure information was not available.

Game (or practice) incidence rates were calculated using the number of games (or practices) as the denominator. This was because data were collected for each game (or practice), with the exact number of minutes spent playing games (or attending practices) not recorded. Confidence intervals $(\mathrm{CIs})^{16}$ for rates were calculated by a method which allowed for the extrabinomial variation associated with repeated injuries in individuals. ${ }^{17}$ This method transforms the data using a variance inflation factor to account for the fact that repeated measures were made on the study participants. Where appropriate, differences in injury rates were tested for significance with a $\chi^{2}$ test, calculated using binomial regression in SAS Proc GENMOD ${ }^{18}$ to account for the correlation due to repeated measures on the cohort. Confidence intervals for rate ratios were calculated using Fieller's theorem. ${ }^{19}$

\section{Results}

A total of 5923 telephone interviews was conducted for 5877 player-weeks of follow up. Detailed information was obtained for 4403 player-games and 8653 player-practices. In 984 (17\%) player-weeks the players reported niggling aches or pains that interfered with their daily activities but did not constitute a new injury event. A total of 671 injury events was reported. For $597(89 \%)$ of these the player 
Table 1 Injury rates and average number of games and practices per person, by gender and grade; Rugby Injury and Performance Project cohort, 1993 season

\begin{tabular}{lccccc}
\hline & Players $(n)$ & $\begin{array}{l}\text { Average number } \\
\text { of games per } \\
\text { person }\end{array}$ & $\begin{array}{l}\text { Game injury rate } \\
\text { (per 100 player-games) } \\
(95 \% \text { CI) }\end{array}$ & $\begin{array}{l}\text { Pverage number of } \\
\text { practices per person }\end{array}$ & $\begin{array}{l}\text { Practice injury rate } \\
\text { (95\% } \text { player-practices) }\end{array}$ \\
\hline All & 345 & 12.7 & $9.9(8.9$ to 11.0$)$ & 24.9 & $1.2(1.0$ to 1.5$)$ \\
Male & 258 & 13.5 & $10.9(9.7$ to 12.2$)$ & 27.8 & $1.3(1.0$ to 1.6$)$ \\
Female & 87 & 10.1 & $6.1(4.6$ to 8.0$)$ & 16.4 & $0.6(0.3$ to 1.1$)$ \\
Senior A & 95 & 14.3 & $14.0(12.0$ to 16.2$)$ & 29.8 & $1.6(0.4$ to 4.1$)$ \\
Senior B & 40 & 11.9 & $10.7(7.5$ to 14.7$)$ & 26.5 & $1.4(0.1$ to 5.5$)$ \\
Colt & 64 & 12.1 & $10.8(8.4$ to 13.5$)$ & 25.4 & $1.2(0.2$ to 4.0$)$ \\
Schoolboy & 54 & 15.2 & $6.2(4.7$ to 8.1$)$ & 28.3 & $0.9(0.1$ to 3.0$)$ \\
Women & 64 & 11.6 & $6.4(4.6$ to 8.6$)$ & 19.6 & $0.7(0.0$ to 3.9$)$ \\
Schoolgirl & 23 & 5.6 & $4.7(1.9$ to 9.3$)$ & 7.3 & 0.0 N/A \\
\hline
\end{tabular}

received medical attention, with $65 \%$ receiving medical attention only and $24 \%$ receiving medical attention and missing a scheduled game or team practice. For $74(11 \%)$ of the injury events the player missed a scheduled game or team practice without receiving any medical attention. Of the 671 injury events, $462(69 \%)$ occurred during rugby games and $107(16 \%)$ during practices. In over a third $(39 \%)$ of the rugby related injury events the player reported a previous injury to the same body site at some time in the past. The remaining $102(15 \%)$ injury events occurred in activities not related to rugby, including other sporting activities $(42 \%)$ and work related activities $(12 \%)$. It is important to note that injury for rugby players occurs in other areas of their life - for example, at work or when participating in other sports. This may impact on the players' ability to take to the field. The remainder of this paper reports details for rugby related injury events.

\section{INCIDENCE RATES}

The overall rate of injury was 72 per 100 players during the competitive club season (that is, $72 \%$ of players reported at least one rugby related injury). The game injury rate was 9.9 per 100 player-games and the practice rate was 1.2 per 100 player-practices (table 1), giving a rate ratio (game to practice injuries) of 8.3 (95\% CI 6.7 to 10.8$)$.

Table 1 presents the incidence of injury by gender and grade and the average exposure to games and practices. The game incidence rate

Table 2 Dsitribution (\%) of rugby related injury events per person by gender, for games and practices, Rugby Injury and Performance Project cohort, 1993 season

\begin{tabular}{lccc}
\hline Number of injury events & $\begin{array}{l}\text { Males } \\
\text { No (\%) }\end{array}$ & $\begin{array}{l}\text { Females } \\
\text { No (\%) }\end{array}$ & $\begin{array}{c}\text { Total subjects } \\
\text { No(\%) }\end{array}$ \\
\hline Games & $68(26.4)$ & $47(54.0)$ & $115(33.3)$ \\
0 & $87(33.7)$ & $30(34.5)$ & $117(33.9)$ \\
1 & $52(20.1)$ & $6(6.9)$ & $58(16.8)$ \\
2 & $28(10.8)$ & $3(3.5)$ & $31(9.0)$ \\
3 & $11(4.3)$ & $1(1.1)$ & $12(3.5)$ \\
4 & $9(3.5)$ & $0(0.0)$ & $9(2.6)$ \\
5 & $3(1.2)$ & $0(0.0)$ & $3(0.9)$ \\
6 & $258(100)$ & $87(100)$ & $345(100)$ \\
Total & 1.48 & 0.63 & 1.26 \\
Mean number of injury events per player & 1.38 & 0.85 & 1.84 \\
Standard deviation & & & \\
Practices & $184(71.3)$ & $78(89.7)$ & $262(75.9)$ \\
0 & $60(23.2)$ & $9(10.3)$ & $69(20)$ \\
1 & $10(3.9)$ & $0(0.0)$ & $10(2.9)$ \\
2 & $2(0.8)$ & $0(0.0)$ & $2(0.6)$ \\
3 & $2(0.8)$ & $0(0.0)$ & $2(0.6)$ \\
4 & $258(100)$ & $87(100)$ & $345(100)$ \\
Total & 0.36 & 0.10 & 0.29 \\
Mean number of injury events per player & 0.67 & 0.31 & 0.36 \\
Standard deviation & &
\end{tabular}

for males (10.9) was higher than that for females (6.1), a rate ratio of $1.8(95 \%$ CI 1.4 to $2.5)$. The difference in game injury rates between the sexes was significant $\left(\chi^{2}=19.88\right.$, $\mathrm{p}<0.001)$. Males also had significantly higher rates of injury in practices than females (rate ratio $2.2(95 \%$ CI 1.2 to 5.6$) ; \chi^{2}=5.30$, $\mathrm{p}=0.021)$. Among the males, the senior $\mathrm{A}$ grade had significantly higher game incidence rates $\left(\chi^{2}=15.11, \mathrm{p}<0.001\right)$ and the schoolboy grade had significantly lower game incidence rates $\left(\chi^{2}=15.92, \mathrm{p}<0.001\right)$ than the other male grades. Note the low number of games played by the schoolgirl grade-fewer than half those of the senior females grade (women) (table 1).

Table 2 depicts the distribution of injury during the season. Most injury events occurred in games, as opposed to practices $(80 \%$ for males, $86 \%$ for females). Forty per cent of males reported more than one game injury event within the season. The overall (games and practices) mean number of injury events per player was 1.84 for males and 0.73 for females. This means that males had, on average, about one more injury in the season than females.

Incidence rates also varied according to position (table 3). For males, in practices, the locks had a significantly higher incidence rate $\left(\chi^{2}=12.26, \mathrm{p}<0.001\right)$, while the inside backs had a significantly lower incidence rate $\left(\chi^{2}=5.04, \mathrm{p}=0.024\right)$, than other positions. There were no significant differences between positional groups for the males in games, but the pattern was similar to that for practices. The rates by position for females were in almost direct contrast with those for the males. The inside backs had the highest incidence rates in both games $\left(\chi^{2}=8.64, p=0.003\right)$ and practices $\left(\chi^{2}=5.99, \mathrm{p}=0.014\right)$ compared with other positions. Female locks, centre backs, and outside backs reported no practice injuries. Injury in practice was rare for females, which is reflected in the large confidence intervals, making any comparisons difficult. The low numbers of players in each group may explain, in part, the large variation between the positions, which was not seen to the same extent in males.

NATURE OF INJURY

A total of 602 rugby related injuries was reported. Table 4 summarises the proportion of injuries by body region and injury type. The lower limb was the body region receiving the most injuries in both games $(42.5 \%)$ and prac- 
Table 3 Injury rates and average number of games and practices per person, by position and gender; Rugby Injury and Performance Project cohort, 1993 season

\begin{tabular}{|c|c|c|c|c|c|}
\hline Position & Players (n) & $\begin{array}{l}\text { Average } \\
\text { number of } \\
\text { games per } \\
\text { person }\end{array}$ & $\begin{array}{l}\text { Game injury rate } \\
\text { (per } 100 \text { player-games) } \\
(95 \% \text { CI) }\end{array}$ & $\begin{array}{l}\text { Average number } \\
\text { of practices per } \\
\text { person }\end{array}$ & $\begin{array}{l}\text { Practice injury rate (per } \\
100 \text { player-practices) } \\
(95 \% \text { CI) }\end{array}$ \\
\hline \multicolumn{6}{|l|}{ Male } \\
\hline Front row & 42 & 14.6 & $11.6(9.1$ to 14.5$)$ & 30.2 & $1.4(0.9$ to 2.1$)$ \\
\hline Locks & 34 & 15.1 & $13.0(9.5$ to 17.3$)$ & 31.0 & $2.5(1.5$ to 3.8$)$ \\
\hline Loose forwards & 60 & 12.8 & $10.6(8.1$ to 13.5$)$ & 26.0 & $0.8(0.5$ to 1.4$)$ \\
\hline Inside backs & 38 & 14.9 & $9.2(6.4$ to 12.6$)$ & 30.8 & $0.6(0.2$ to 1.4$)$ \\
\hline Centre backs & 41 & 12.0 & $10.1(7.1$ to 13.8$)$ & 24.5 & $1.9(0.9$ to 3.4$)$ \\
\hline Outside backs & 43 & 12.8 & $11.1(8.2$ to 14.5$)$ & 26.3 & $1.0(0.5$ to 1.6$)$ \\
\hline \multicolumn{6}{|l|}{ Female } \\
\hline Front row & 20 & 10.6 & $3.8(1.9$ to 6.8$)$ & 19.0 & $1.1(0.3$ to 2.5$)$ \\
\hline Locks & 11 & 11.8 & $4.6(1.9$ to 9.4$)$ & 19.2 & $0.0 \mathrm{~N} / \mathrm{A}$ \\
\hline Loose forwards & 17 & 9.9 & $8.3(3.6$ to 15.9$)$ & 16.0 & $0.4(0.0$ to 1.9$)$ \\
\hline Inside backs & 11 & 11.8 & $12.3(7.7$ to 18.2$)$ & 18.3 & $1.5(0.4$ to 3.8$)$ \\
\hline Centre backs & 11 & 10.5 & $5.2(1.9$ to 11.0$)$ & 14.3 & $0.0 \mathrm{~N} / \mathrm{A}$ \\
\hline Outside backs & 16 & 8.8 & 3.5 (1.1 to 8.2$)$ & 14.8 & $0.0 \mathrm{~N} / \mathrm{A}$ \\
\hline
\end{tabular}

tices $(58.4 \%)$. There were significantly more injuries to the lower limb in practices $\left(\chi^{2}=10.18, \mathrm{p}=0.001\right)$ than injuries to other body regions. Within the lower limb category, the knee $(12 \%$ of all injuries), thigh $(8 \%)$, and ankle $(5 \%)$ were the most commonly injured sites in games, while in practices lower limb injuries most commonly occurred to the ankle $(14 \%$ of all injuries), thigh (13\%), and hamstring $(11 \%)$. Injuries to the head and face occurred more often in games than in practices $\left(\chi^{2}=8.16, p<0.001\right)$.

A higher proportion of sprain and strain injuries occurred in practices than in games $\left(\chi^{2}=31.72, \mathrm{p}=0.001\right)$. Haematomas $\left(\chi^{2}=9.41\right.$, $\mathrm{p}<0.001)$ and lacerations $\left(\chi^{2}=4.89, \mathrm{p}=0.02\right)$ occurred more often in games than in practices compared with other injury types.

Lacerations occurred most commonly to the head and face, whereas sprains/strains and haematomas/bruising occurred predominantly to the lower limb. The most common injuries in games were sprained/strained knees ( $8 \%$ of all game injuries), ankles (7\%), and shoulders $(6 \%)$. In practices sprains/strains to the thigh ( $13 \%$ of all practice injuries), ankle $(12 \%)$, and hamstring $(11 \%)$ were the most common injuries.

Figure 1 describes the injuries by player position. Forwards had more injuries to the head/face $\left(\chi^{2}=5.00, \mathrm{p}=0.025\right)$ and neck $\left(\chi^{2}=4.47, \mathrm{p}=0.034\right)$ in games than in practices. Game injuries to the head/face were lacerations (48\%), concussions (28\%), haematomas $(17 \%)$, and fractures ( $7 \%)$. Game injuries to the neck were sprains/strains $(86 \%)$, haematomas $(11 \%)$, and one dislocation (3\%). Forwards also received more sprains/strains $\left(\chi^{2}=9.21, \mathrm{p}<0.001\right)$ and more lower limb injuries $\left(\chi^{2}=8.59, \mathrm{p}<0.001\right)$ in practices, compared with other injury types and other body sites.

There were no differences in the body sites injured in games and practices, for the backs. With respect to injury type, the backs received more haematomas $\left(\chi^{2}=25.76, p=0.001\right)$ in games than in practices. Backs also had more sprains/strains in practices $\left(\chi^{2}=25.76\right.$, $\mathrm{p}=0.001)$ compared with other injury types. Grade of play, gender, and specific playing position were not examined in relation to site and type of injury because of small group sizes.

Forty five per cent of the injury events resulted in an injury that interfered with what the player had planned to do the next day. On the Abbreviated Injury Scale, ${ }^{14} 433$ (76.7\%) injuries were coded as minor severity (AIS-1), $129(22.8 \%)$ as moderate severity (AIS-2), and three $(0.5 \%)$ as serious (AIS-3).

Table 4 Injury type by body region, Rugby Injury and Performance Project cohort, 1993 season

\begin{tabular}{|c|c|c|c|c|c|c|c|}
\hline \multirow[b]{2}{*}{ Type } & \multicolumn{7}{|l|}{ Body region } \\
\hline & $\begin{array}{l}\text { Head and } \\
\text { face No (\%) }\end{array}$ & $\begin{array}{l}\text { Neck } \\
\text { No (\%) }\end{array}$ & $\begin{array}{l}\text { Upper limb } \\
\text { No (\%) }\end{array}$ & $\begin{array}{l}\text { Trunk } \\
\text { No }(\%)\end{array}$ & $\begin{array}{l}\text { Lower limb } \\
\text { No }(\%)\end{array}$ & $\begin{array}{l}\text { Unidentified } \\
\text { No }(\%)\end{array}$ & $\begin{array}{l}\text { Total } \\
\text { No }(\%)\end{array}$ \\
\hline \multicolumn{8}{|l|}{ Game } \\
\hline Sprain/strain & - & $24(5.0)$ & $64(13.1)$ & $21(4.3)$ & $117(23.9)$ & $2(0.4)$ & $228(46.7)$ \\
\hline Haematoma & $14(2.9)$ & $3(0.6)$ & $21(4.3)$ & $8(1.6)$ & $69(14.1)$ & $2(0.4)$ & 117 (23.9) \\
\hline Laceration & $38(7.8)$ & $0(0.0)$ & $0(0.0)$ & $2(0.4)$ & $2(0.4)$ & $1(0.2)$ & $43(8.8)$ \\
\hline Fracture & $6(1.2)$ & $0(0.0)$ & $14(2.9)$ & $3(0.6)$ & $4(0.8)$ & $1(0.2)$ & $28(5.7)$ \\
\hline Dislocation & $0(0.0)$ & $1(0.2)$ & $17(3.5)$ & $0(0.0)$ & $0(0.0)$ & $0(0.0)$ & $18(3.7)$ \\
\hline Concussion & $22(4.5)$ & - & - & - & - & - & $22(4.5)$ \\
\hline Other identified & $8(1.6)$ & $4(0.8)$ & $1(0.2)$ & $4(0.8)$ & $12(2.5)$ & $0(0.0)$ & $29(5.9)$ \\
\hline Unknown & $0(0.0)$ & $0(0.0)$ & $0(0.0)$ & $0(0.0)$ & $4(0.8)$ & - & $4(0.8)$ \\
\hline Total & $88(18.0)$ & $32(6.6)$ & $117(24.0)$ & $38(7.7)$ & $208(42.5)$ & $6(1.2)$ & $489(100)$ \\
\hline \multicolumn{8}{|l|}{ Practice } \\
\hline Sprain/strain & - & $3(2.6)$ & $16(14.2)$ & $9(7.9)$ & $58(51.3)$ & $0(0.0)$ & $86(76.1)$ \\
\hline Haematoma & $2(1.8)$ & $0(0.0)$ & $6(5.3)$ & $0(0.0)$ & $2(1.8)$ & $2(1.8)$ & $12(10.7)$ \\
\hline Laceration & $3(2.6)$ & $0(0.0)$ & $0(0.0)$ & $0(0.0)$ & $0(0.0)$ & $0(0.0)$ & $3(2.6)$ \\
\hline Fracture & $0(0.0)$ & $0(0.0)$ & $1(0.9)$ & $0(0.0)$ & $2(1.8)$ & $0(0.0)$ & $3(2.6)$ \\
\hline Dislocation & $0(0.0)$ & $0(0.0)$ & $1(0.9)$ & $0(0.0)$ & $0(0.0)$ & $0(0.0)$ & $1(0.9)$ \\
\hline Concussion & $1(0.9)$ & - & - & - & - & - & $1(0.9)$ \\
\hline Other identified & $2(1.8)$ & $0(0.0)$ & $0(0.0)$ & $0(0.0)$ & $4(3.5)$ & $1(0.9)$ & $7(6.2)$ \\
\hline Total & $8(7.1)$ & $3(2.6)$ & $24(21.3)$ & $9(7.9)$ & $66(58.4)$ & $3(2.7)$ & $113(100)$ \\
\hline
\end{tabular}


Games

Injuries to backs $(n=212)^{\dagger}$

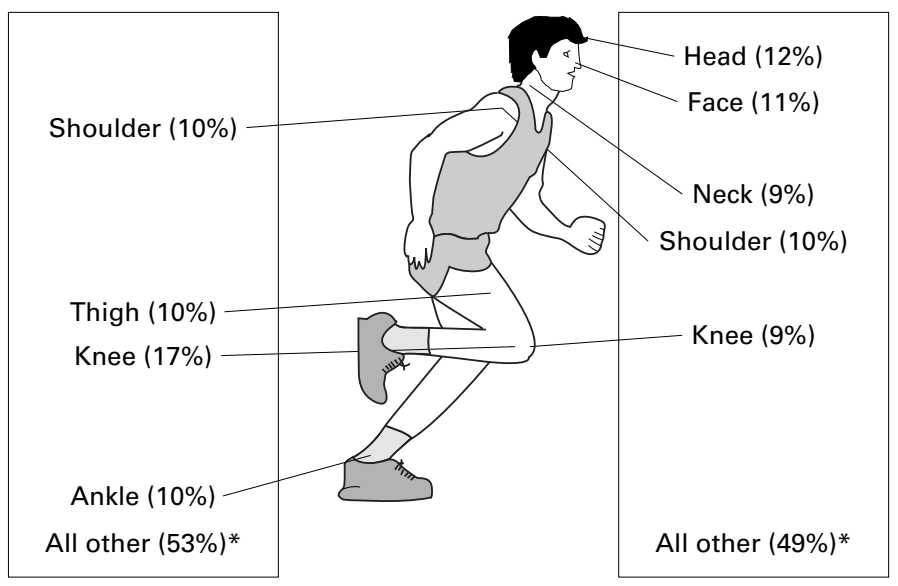

Practices

Injuries to backs $(n=44)^{\dagger}$

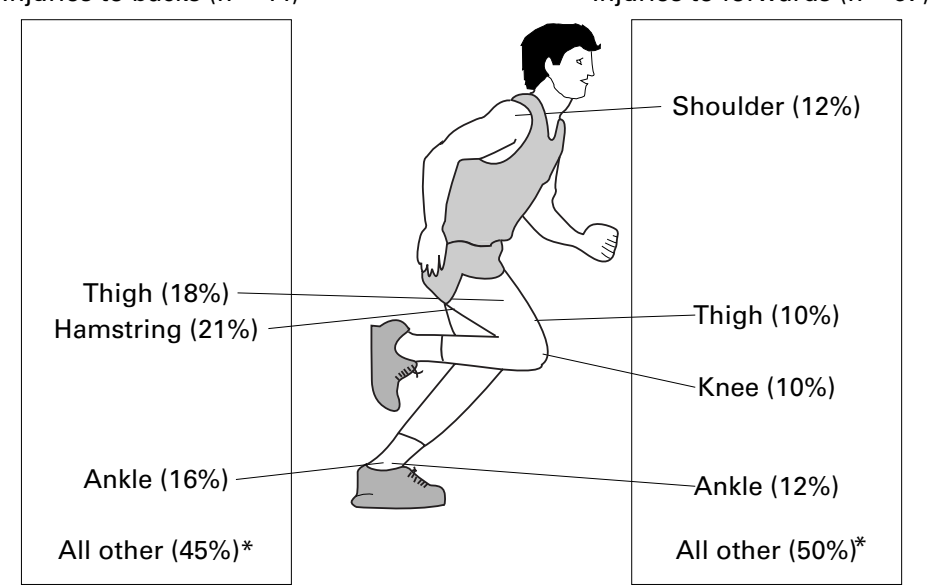

Figure 1. Injuries by position, Rugby Injury and Performance Project cohort, 1993. *All other injury sites reported; fInformation missing for six injury sites by position.

\section{CIRCUMSTANCES OF INJURY}

Injury events occurred in club competition games $(87 \%)$, pre-season club games $(8 \%)$, and representative games (5\%). Most representative games are played after the competitive club season.

The tackle was the phase of play in which most game injury events occurred (40\%), followed by rucks $(17 \%)$, mauls $(12 \%)$, back play $(9 \%)$, scrums $(7 \%)$, and other $(15 \%)$ phases of play. In tackles, ball carriers (49\%) and tacklers (47\%) were represented in almost equal proportion, with support players accounting for the remainder of these events (4\%). Figure 2 summarises the body sites for injuries resulting from tackle injury events.

Forty six per cent of game injury events occurred during the first half of play and $40 \%$ during the second half. For the remaining injury events $(14 \%)$ this information was not reported. When examined in 10 minute intervals the injuries were found to have occurred evenly throughout the game.

Foul play was reported as the cause of $13 \%$ of the game injury events. In most of these cases $(69 \%)$ no penalty was called. The

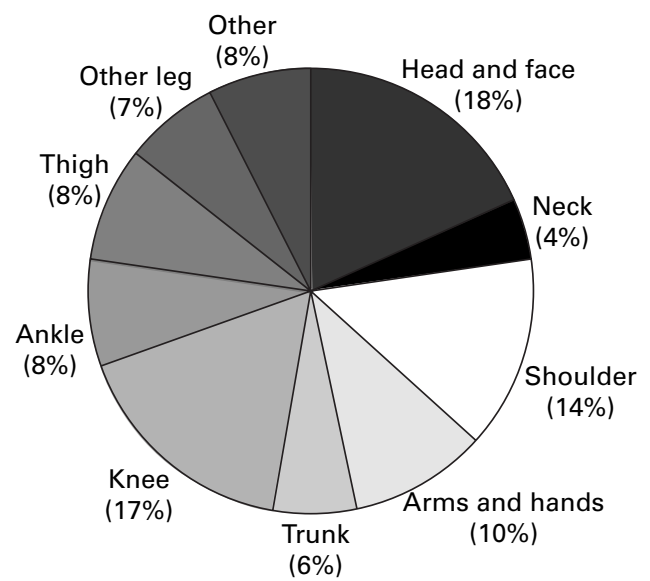

Figure 2 Body site for injuries sustained in tackles (game injury events only, $n=180$ ), Rugby Injury and Performance Project cohort, 1993.

proportion of foul play injury events occurring within each grade did not differ significantly. When foul play injuries were examined further, more injuries to the head (including the face and eye $)\left(\chi^{2}=28.48, \mathrm{p}=0.001\right)$ and more lacerations $\left(\chi^{2}=27.86, \mathrm{p}=0.001\right)$ were found compared with non-foul play injuries. Of the foul play injuries to the head, $65 \%$ were lacerations, $17 \%$ concussion, $9 \%$ fractures, and $9 \%$ bruising.

In practices a large proportion (45\%) of injury events occurred while the player was taking part in practice drills that did not involve a specific phase of play. Where the phase of play was identified, back play (18\%), tackles (12\%), and scrums ( $9 \%$ ) featured prominently. Forty five per cent of injuries sustained in practices occurred within the first 40 minutes.

CONCUSSION

Because of the potentially serious long term consequences of concussion and the three week stand down rule that applies in New Zealand ${ }^{20}$ this type of injury was examined in detail. Twenty two of the players reported sustaining concussion in a game. Of these, 30\% had had a previous injury to the head severe enough to require medical attention. Most of the concussions occurred in the tackle (64\%). Just under half of these tackle concussions (46\%) occurred to the tackler, $36 \%$ to the ball carrier, and $18 \%$ to support players. Nineteen players $(86 \%)$ reported being placed on a three week stand down as a result of the concussion. Fifteen of these players attended practices within three weeks of the injury. Two of the 19 players reported playing in a game within two weeks after the injury. The remaining players did not play until three or more weeks after the injury.

Almost all of the players with a concussion had received medical treatment for the injury by the time of the interview (95\%), with nine ( $41 \%$ ) stating that they planned to seek further treatment. At the time of the injury event, 16 $(72 \%)$ players were not wearing any protective equipment, while the remaining players were wearing either a mouthguard $(14 \%)$ or headgear $(14 \%)$. Nine $(41 \%)$ players continued 
playing in the game in which the injury was sustained. In four cases the player considered the concussion to be the result of foul play.

\section{Discussion}

Rugby injury is common, as can be seen by the high proportion of this cohort who sustained injuries during the 1993 competitive club season $(72 \%)$ and during the previous season $(82 \%) .{ }^{4}$ Despite the vigorous nature of the game, it is of concern that such a large proportion of players report injury and that such large numbers of injuries are reported for each season. In both the 1993 season and the previous season over 550 rugby related injuries were reported by the cohort of 356 players. The long term effects of these injuries are not known. Of concern is the potential risk for long term musculoskeletal effects and the cumulative effects of trauma to the head.

In this study the male players sustained higher rates of injury, both for games and practices, with rate ratios of 1.8 and 2.2 respectively. These results are consistent with the findings of the only other study to compare the injury experience of male and female rugby players. ${ }^{10}$ After converting the results reported in that study to rates per 100 player-games, a rate ratio for games of $1.6(9.5: 5.9)$ was obtained. Women's rugby has only recently become an organised part of the sport, and differences in the way in which the game is played by women may explain the lower injury rates. As increasing numbers of women play the game and the level of competition intensifies, the present differences between the sexes may become less pronounced. Another possible explanation for the lower injury rate for the women is that forces involved in player impacts may be lower. The momentum generated by the women in the RIPP cohort was, on average, lower than that generated by the male players. The women had, on average, lower body mass and slower sprint speeds than the men. ${ }^{21} \mathrm{~A}$ challenge for rugby is to avoid an increase in the incidence of injury for women players to the level of their male counterparts.

Injury rates examined within player groups showed higher rates for the more senior grades (that is, injury rates were higher in "higher" grades). This result, also, is consistent with previous reports. ${ }^{38}$ The RIPP injury rates are highest for the most senior grades of the game where skills, fitness, experience, and intensity of the game are also expected to be highest. Williams and Blake have offered several possible explanations for this, including the increased size and strength of players, higher level of competitiveness, increased vigour, increased aggression, more foul play, and more matches during the season. ${ }^{22}$

The literature is somewhat equivocal about which playing positions have the greatest risk of injury. No other studies have reported incidence rates by position for women players. For men, Hughes and Fricker reported finding no difference between forwards and backs. ${ }^{2}$ The loose forwards and centres, however, were disproportionately represented among those injured in Australian first grade rugby. ${ }^{2}$ Garraway and MacLeod reported finding no significant differences in the proportion of injury episodes according to position. ${ }^{3}$ In contrast, Clark, Roux and Noakes reported that, for South African adult rugby players, the most vulnerable positions were hooker, wing, and fullback. ${ }^{1}$ Our results differ in several respects from those above and do not support our original hypothesis. We found significant differences between injury rates for positional groups, in both games and practices for females, and in practices for males. Although there were no significant differences between rates for males in games, there was variation between positions, with locks having the highest rate, followed by front row forwards, and outside backs. In none of the earlier studies were locks ranked first in order of frequency of injury. The positions identified by Clark et $a l^{1}$ as having the highest incidence of injury fall into the categories ranked second and third in the present study - that is, hookers (front row) and wings and fullbacks (outside backs).

One explanation for the differences discussed above is that the earlier studies reported the proportion of injuries attributable to the different positions, whereas our study reported the injury rates by positional categories. Because injury rates take exposure to risk into account (measured as number of games played in the present study), this is the preferred method of reporting when comparisons between groups are to be made.

Forwards received significantly more head, face, and neck injuries in games than in practices, indicating that the causes and types of these injuries should be investigated further. In this study small numbers prevented a detailed analysis being performed. Research specifically investigating injuries by player position, with adequate power to make statistical comparisons, is required. If lacerations and abrasions to the head and face are common in the forwards, then the promotion of the use of headgear would be a suitable intervention. Targeting foul play may also be an appropriate intervention.

Many of the present findings are consistent with those of previous studies, including such findings as the greater incidence of injury in games compared with practices, sprains and strains being the most common type of injury, the lower limb being the anatomical region most commonly injured, and the tackle being the phase of play in which the greatest proportion of injuries occur. ${ }^{1-47810}$ This suggests that these factors are constant both between rugby playing countries and over time. Given this consistency, any interventions targeting these areas are likely to have a greater impact if they are agreed internationally.

Previous research suggested that physiological fatigue may be a contributing factor for rugby injury. ${ }^{912}$ One would expect more injuries to occur in the later stages of a game. In this study, however, injury events occurred evenly throughout the game. We therefore found no evidence to suggest that fatigue contributed to the rugby injuries reported by this cohort. 
Another area in which there is scope for preventive action is that of foul play. Foul play was found to be associated with $13 \%$ of the game injury events reported in this study. There were no differences in the proportion of foul play incidents occurring across grades. Lewis reported the involvement of foul play in $32.7 \%$ of injuries to men, $19 \%$ of injuries to youth, and $17 \%$ of injuries to women. ${ }^{10}$ Reducing foul play by stricter refereeing of games may be effective in reducing injury. The responsibility for reducing foul play, however, does not lie solely with the referee. Players must accept personal responsibility for their actions, as must coaches for the messages they provide to players. Administrators too have a role. The establishment of judicial committees to deal with this issue and the awarding of fair play prizes are recent New Zealand initiatives, which seem to have gained wide acceptance. Reducing foul play will not only have the benefit of reducing injury but will also make for a "cleaner" game that is more attractive to supporters. This an important consideration for a sport that is competing with other major sports for spectator support.

Concussive injuries were reported by a small proportion of the cohort. Most players were "stood down" as a result of their injury, though there seems to be some confusion over the accepted stand down period. Some players returned to practising and playing in rugby games within three weeks of the injury. A New Zealand Rugby Football Union directive states that "It is mandatory that a player who has suffered concussion stand down for a minimum period of three weeks during which all rugby, including practice, must also be suspended ( $p$ 61)". ${ }^{20}$

Most of the players sustaining concussion were not wearing protective equipment at the time of injury. Mouthguards are considered to provide protection against concussion ${ }^{23}$ by dissipating impact forces through the jaw. Headgear is recommended for protection against lacerations and abrasions, but it may also provide limited protection from impact injury. It has not been determined if the use of headgear in rugby union protects against concussion. ${ }^{24}$ The presence of appropriately trained first aid or sports medicine personnel at matches may assist in the detection of concussion and help in preventing the player from returning to the field of play if concussion is diagnosed.

\section{Conclusion}

Rugby injury is common in competitive club players. The long term effects of these injuries are not known. From a public health standpoint it is clear that participation in rugby was the predominant source of injury for our study subjects. Therefore, this is the prime area to address if we are to reduce the toll of injury in their lives. Although the physical nature of rugby union contributes to the high rate of injury, this does not provide a complete explanation, as variations in rates of injury are seen by both grade and gender. Dealing with the issue of foul play, and identifying the causes of injury in the tackle and to the lower limb, might contribute to an overall reduction in injury. For researchers, the challenge is to achieve some consistency in the reporting of results, particularly in relation to injury definition and rates. This will allow for meaningful comparison of results between studies, which will facilitate the development and evaluation of interventions.

The Rugby Injury and Performance Project was funded by a grant from the Accident Rehabilitation and Compensation Insurance Corporation (ACC). The Injury Prevention Research Unit is jointly funded by the Health Research Council of New Zealand and the ACC. The views expresily reflect those of the those of the authors

bove organisations.

The authors acknowledge the important contribution of their co-investigators throughout this project: Ken Quarrie, Barry Wilson, Martin Toomey, Phil Handcock, Ken Hodge, Michael Feehan, Jean Simpson, Katrina Sharples, and Sheila Williams. The authors thank the following people and organisations for their support and assistance: Ms Pamela Jemmett (for assistance with graphics), the players, interviewers, Otago Rugby Football Union, and New Zealand Rugby Football Union.

1 Clark DR, Roux C, Noakes TD. A prospective study of the incidence and nature of injuries to adult rugby players. $S$ Afr Med $¥ 1990 ; 77: 559-62$.

2 Hughes DC, Fricker PA. A prospective survey of injuries to first-grade rugby union players. Clin $\mathcal{F}$ Sport Med 1994;4: $249-56$

3 Garraway M, MacLeod D. Epidemiology of rugby football injuries. Lancet 1995;345:1485-7.

4 Gerrard DF, Waller AE, Bird YN. The New Zealand Rugby Injury and Performance Project: II. Previous injury experience of a rugby-playing cohort. $\mathrm{Br} \quad \mathcal{F}$ Sports $\mathrm{Med}$ 1994;28:229-33.

5 Accident Rehabilitation and Compensation Insurance Corporation. Injury statistics 1994 and 1995. Wellington: Accident Rehabilitation and Compensation Insurance Corporation, 1995.

6 Hume PA, Marshall SW. Sport injuries in New Zealand: exploratory analysis. New Zealand fournal of Sports Medicine 1994;22:18-22.

7 Dalley DR, Laing DR, McCartin PJ. Injuries in rugby football, Christchurch 1989. New Zealand fournal of Sports Medicine 1992;20:2-5.

8 Seward H, Orchard J, Hazard H, et al. Football injuries in Australia at the elite level. Med f Aust 1993;159:298-301.

9 Reilly T, Hardiker R. Somatotype and injuries in adult student rugby football. F Sports Med Phys Fitness 1981;21:18690

10 Lewis E. Rugby injuries: do men and women sustain different injuries? SportCare fournal 1994;1:8-9.

11 Dalley DR, Laing DR, Rowberry JM, et al. Rugby injuries: an epidemiological survey, Christchurch 1980. New Zealand fournal of Sports Medicine 1982;10:5-17.

12 Wekesa M, Asembo JM, Njororai WWS. Injury surveillance in a rugby tournament. Br f Sports Med 1996;30:61-3.

13 Waller AE, Feehan M, Marshall SM, et al. The New Zealand Rugby Injury and Performance Project: I. Design and methodology of a prospective follow up study. Br $\mathcal{F}$ Sports Med 1994;28:223-8.

14 Last JM. A dictionary of epidemiology. 2nd ed. Oxford: Oxford University Press, 1988.

15 Association for the Advancement of Automotive Medicine. The Abbreviated Injury Scale. Des Plaines: Association for The Abbreviated Injury Scale. Des Plaines: Associti

the Advancement of Automotive Medicine, 1990.
Armitage P, Berry G. Statistical methods in medical research. Armitage P, Berry G. Statistical methods in
2nd ed. Oxford: Blackwell Scientific, 1988.

17 Rao JNK, Scott AJ. A simple method for the analysis of clustered binary data. Biometrics 1992;48:577-85

18 SAS Institute Inc. SAS Technical Report P-243, SAS/STAT Software:The GENMOD procedure, Release 6.09, Cary, NC: SAS Institute, 1993.

19 Stokes ME, Davis CS, Koch GG. Categorical data analysis using the SAS system. Cary, NC: SAS Institute, 1995.

20 Guy RA, Gentry SE, Stewart JJ, et al, eds. Coaching accreditation manual level 1. Wellington: New Zealand Rugby Football Union, 1992

21 Quarrie KL, Handcock P, Waller AE, et al. The New Zealand Rugby Injury and Performance Project: III. Anthropometric and physical performance characteristics Anthropometric and physical performance

of players. Br f Sports Med 1995;29:263-70.
22 Williams D, Blake S. Rugby injuries - a case study. Dunedin: University of Otago, 1983. (A special topic submitted in partial completion of the Bachelor of Physical Education.)
Fricker JP, O'Neill ML. Dental problems. In: Bloomfield J, Fricker JP, O'Neill ML. Dental problems. In: Bloomfield J,
Fricker PA, Fitch KD, eds. Textbook of science and medicine in sport. Melbourne: Blackwell Scientific, 1992:303.

24 Wilson BD. Protective headgear in rugby union. Sports Med 1998;25:333-7 